\title{
Some Effects of Task Type on the Relation between Communicative Effectiveness and Grammatical Accuracy in Intensive ESL Classes $^{1}$
}

\section{Carolyn E. Turner and John A. Upshur}

Two language characteristics, Communicative Effectiveness (CE) and Grammatical Accuracy (GA), were investigated in 130 grade 5 students in intensive ESL classes. Using different types of elicitation tasks in a cross-sectional study, it was found that $C E$ and $G A$ are not independent, but the relation between the variables differs as a function of task type. In a short-utterance sentence production task, CE and GA appear to develop simultaneously. In an extended-discourse story retell, GA reaches a plateau with some subjects while CE continues to develop. Suggestions for classroom application of these findings are discussed.

In this article we look at the relation between communicative effectiveness (CE) and grammatical accuracy (GA) across two different types of speaking tasks. The term communicative effectiveness is used in the same sense as used by Yule, Powers, and MacDonald (1992) to indicate success in information transfer regardless of how it is achieved. The term is used in language testing (Yorozuya \& Oller, 1980; Bachman \& Palmer, 1984) to refer to a holistic judgment of success in communication while avoiding any assumptions about the kinds of knowledge and ability that lead to that success. CE is related, therefore, to the communicative outcomes of language events; GA is related to the linguistic forms employed in those events. Specifically, we are concerned with the relation between $\mathrm{CE}$ and GA in tasks that require short utterances with high information content and tasks that require longer utterances with greater textual redundancy.

The primary aim of modern second language courses is to have students become effective communicators. It is widely agreed that communicative effectiveness (also called communicative competence and communicative language ability) is not a simple ability. Effectiveness in communication is enhanced, for example, by range of vocabulary, grammatical knowledge, cultural awareness, topic familiarity, means by which one can compensate for linguistic limitations, and so forth. A number of writers have proposed formal theories and descriptions of CE (Bachman, 1990, 1991; Canale, 1983; Canale \& Swain, 1980; Hymes, 1972; Munby, 1978; Savignon, 1983). 
Despite high agreement on the aims of language teaching and on the complexity of $\mathrm{CE}$, there is much less accord on how to teach for $\mathrm{CE}$ or on what "components" of CE should receive special attention in the communicative classroom.

The research reported here is part of a larger investigation of second language (L2) learning in an intensive ESL communicative program (see Spada \& Lightbown, 1989, for a description of the program).

\section{Background}

Second language teaching continues to be influenced by contrasting views concerning the most effective way to learn L2 in classroom settings. Even though attention is currently on communicative language teaching, the inclination toward a strong or major focus on grammatical accuracy remains evident in many classrooms.

One view holds that an increase in GA results in augmentation of CE. This view is implicit in courses that focus on language usage. It is influenced by structural linguistics and is in line with the traditional approach to second language teaching. As a rule, classroom practices emphasize the study and analysis of language form, stress the mastery of discrete elements, and tend to be teacher-dominated, with the purpose of guiding students toward grammar accuracy (Brumfit, 1984).

The contrasting view holds that application of communicative strategies leads to an increase in $\mathrm{CE}$, and this provides the requisite precondition for development of GA. This view is implicit in courses that emphasize language use (i.e., a communicative language curriculum). In general, classroom practices focus on activities in which students are actively interacting with, and using, language to construct meaning for themselves and others. Stress is placed on the development of skills and strategies to help guide students to participate in language experiences. Activities tend to be learner-centered and meaning-based to encourage language use leading to fluency (Brumfit, 1984).

Teaching practices show variation across the two views concerning the development of language ability. In addition, there is variation within these views. Cummins and Swain (1986) suggest that much more research is needed in order to complete the theories that underlie communicative language teaching practices.

Second language acquisition (SLA) research can provide insight into L2 learning in classroom settings. Scarcella and Oxford (1992), in a review of the SLA research literature, posit their Language-Promoting Interaction Hypothesis, which states that "teachers can best help students acquire language by providing students with numerous supports ... and assistance in communicating what they cannot communicate alone" (p. 45). Drawing on earlier concepts from Tharp and Gallimore $(1988,1989)$ and Vygotsky $(1956)$, they 
suggest that learning occurs when linguistic abilities are "stretched" through the provision of required skilful "assistance" at specific times when students require this assistance. This help can vary from aid concerning grammatical structures and lexical items to teaching of learning strategies and direction of attention.

Following their own review of the SLA literature, Lightbown and Spada (1993) summarize:

Classroom data from a number of studies offer support for the view that form-focused instruction and corrective feedback provided within the context of a communicative program are more effective in promoting second language learning than programs which are limited to an exclusive emphasis on accuracy on the one hand or an exclusive emphasis on [the communication of meaning] on the other. (p. 105)

Fotos (1994) summarizes the "compelling body of evidence" supporting the position that focus-on-form instruction targeting specific language components is related to acquisition of those components (p. 323). See, for example, Buczowska and Weist (1991); Doughty (1991).

Given the recommendations for attention to form in communicative language teaching, the question addressed in this study is: What is the relation between CE and GA among the learners in one communicative ESL program? Do the two abilities develop hand-in-hand or does one slow down or stop while the other goes ahead?

\section{Method}

\section{Participants}

Participants for this study were 130 French speakers enrolled in grade 5 in five schools in the Montreal metropolitan area. All classes were using the Greenfield Park Curriculum for Intensive ESL (Bolduc, n.d.). This curriculum is communicative and theme-based, and classroom input focuses on meaning, genuine questions, and negotiation of meaning. References are made to grammatical accuracy as the situation arises and the teacher sees a need. Students are immersed in five hours of ESL instruction per day for a period of five months of one school year. All other required academic subjects are given in French during the other months of the school year. At the time of the study they had completed approximately four months of the intensive ESL course. In the previous school year these students had started their regular ESL program of 120 minutes per week.

Participants were obtained through teachers volunteering the collaboration of their classes. Students were not required to participate, but with a single exception did so enthusiastically. 


\section{Instruments}

This study employed four measures of speaking ability developed especially for the investigation of this population. A measure is defined here as a speech elicitation procedure and a rating scale. Two elicitation procedures were used; two rating scales were developed for each procedure, yielding a total of four measures. The first elicitation procedure was a short-utterance production task. The other was an extended-discourse story retell task. These different sorts of tasks were selected because we thought that they would demand different abilities for their performance, would produce texts that differed in a number of discourse characteristics, and would elicit speech samples that would present different requirements for interpretation (see, e.g., Enkvist, 1990; Linn, Baker, \& Dunbar, 1991). Rating scales were designed to assess CE and GA for speech elicited by each of the procedures.

\section{Tasks}

Initially the test developers reviewed curricular materials and methods. Then they constructed tasks that were designed to incorporate only linguistic, notional, functional, and thematic material from the students' program. They made certain also that all test methods were familiar from regular classroom experience. A feasibility study was conducted and the elicitation procedures were revised accordingly (Turner \& Upshur, 1992).

The first task required production of single sentences. Assisted by a test examiner, students were asked to make sentences in response to visual cue cards. There were 15 items (i.e., cue cards). Examples can be found in Appen$\operatorname{dix} \mathrm{A}$.

The second task was a story retell. Each student watched a 2.5-minute cartoon videotape, Arnold of the Ducks (Columbia Broadcasting System, 1990). Immediately after viewing, the students were asked to relate the story to a test interviewer. The aim was to obtain at least a one-minute narration. If students were unable to produce this, a sequence of prompts was employed to elicit a ratable speech sample (e.g., "Do you remember anything else?").

\section{Rating Scales}

Both tasks were rated by scales that had been empirically developed from the data collected. For each task, two rating scales were constructed, one for GA and the other for CE. Each of the scales was constructed empirically using a sample of responses from students in the schools where the study was conducted. A different four-member team of scale developers devised each of the four scales. A team listened to a set of 10 tape-recordings of student speech for the test they were working with. For the CE scales, the process was initiated through having the team first rank the tapes holistically on the basis of effectiveness of communication. The GA scale was similarly developed from holistic rankings of samples on the basis of grammatical accuracy. Then 
the samples were analyzed for features that distinguished levels of performance. (For rationale and a complete description of development procedures of the scales, see Upshur \& Turner, in press.) Each scale produced in this fashion consists of a small set of questions the rater asks about the presence of particular features in the speech sample being rated. Answers to two or three Yes-No questions lead to a rating for the sample. The single sentences are rated using a 4-point scale, and the story retell using a 6-point scale. The four scales can be seen in Appendix B. ${ }^{3}$

\section{Procedure}

Students were individually called out from their regular classroom activities for testing. All responses were tape-recorded for subsequent scoring. After all testing was completed each of the four measures was scored independently by two members of the team that had developed the scale for that measure. Scores of the two raters were combined. Scores for the GA and CE measures on the sentence production task, therefore, had a minimum of 30 (2 raters $x 15$ items with a minimum score of 1 point per item) and a maximum possible score of 120 ( 2 raters $\times 15$ items $\times 4$ points per item). Some items for some students could not be rated. These included unreached items (i.e., when a student stopped responding before the end of the test) and items unscorable because of quality of recording (e.g., student turned away from the microphone or an intrusion of ambient noise). It was unreasonable to assume that performance on these items would be minimal. Therefore, they were assigned a score equal to the average score attained on all of the scorable items on the test. Minimum and maximum possible scores for the story retell were 2 and 12 .

Scores on each of the four measures were calculated for all subjects. Means and standard deviations were computed. Reliabilities were computed for each of the measures. Correlations were computed between GA and CE for the short-utterance and the story retell tasks. Scatter plots of the correlations were examined for linearity of relations, that is, to see whether scores on GA and CE both increase at the same rate or whether one measure seems to slow down while the other continues to improve.

\section{Results}

Eighty students completed the sentence construction task, and 101 the story retell. Summary statistics are presented in Table 1 . These indicate that both tests were appropriate for this sample of students. There were no obvious boundary effects, and scores were not tightly bunched.

Cronbach $\alpha$ reliabilities were good for brief oral tests taken by students at a single grade level. For Sentence Construction the reliability of the pooled rating of two judges was .97 for GA and .91 for CE. The corresponding reliabilities for the Story Retell were .87 and .81 . 
Table 1

Two Ability Measures on Two Test Tasks

(Two Pooled Ratings)

\begin{tabular}{lccccc}
\hline Task & Scale & $n$ & $\begin{array}{c}\text { Max Score } \\
\text { Possible }\end{array}$ & Mean & $S D$ \\
\hline $\begin{array}{l}\text { Sentence } \\
\text { Construction }\end{array}$ & GA & 80 & 120 & 77.7 & 16.1 \\
Sentence & & & & & \\
Construction & CE & 80 & 120 & 56.8 & 13.5 \\
Story Retell & GA & 101 & 12 & 6.6 & 2.5 \\
Story Retell & CE & 101 & 12 & 6.9 & 2.7 \\
\hline
\end{tabular}

The Pearson correlation between pooled ratings of GA and CE for Sentence Construction was .79, for Story Retell .74. In examining scatterplots for the two tasks, the relation appeared to be linear for Sentence Construction; for Story Retell, however, the relation was nonlinear with CE increasing more rapidly than GA at the higher levels. Idealized curves to show these relations are depicted in Figures $1 \mathrm{a}$ and $1 \mathrm{~b}$.

\section{Discussion}

These findings demonstrate a clear difference in the relation between GA and $\mathrm{CE}$ for two different test tasks. This is not surprising if communicative effectiveness is made up of many different components, that is, if there are a number of different abilities that all contribute to CE. It is quite reasonable that different communicative tasks would make use of different component abilities.

A primary difference between the two tasks employed in this study was the amount of speech elicited in each response. The length (and organization) of responses has implications for comprehensibility of the subjects' speech. In the story retell, initial sentences provide additional context for the comprehension and interpretation of succeeding sentences. That is, the story retells have a high degree of textual redundancy. For the sentence construction task, students produce a single sentence for each item. There is, therefore, no extended discourse to aid listeners in comprehension of student responses.

In the story retell task, some subjects who scored high on $\mathrm{CE}$ also scored high on GA. There were others, however, who achieved high CE scores but did not score high on GA. It seems that with an extended discourse task, GA 


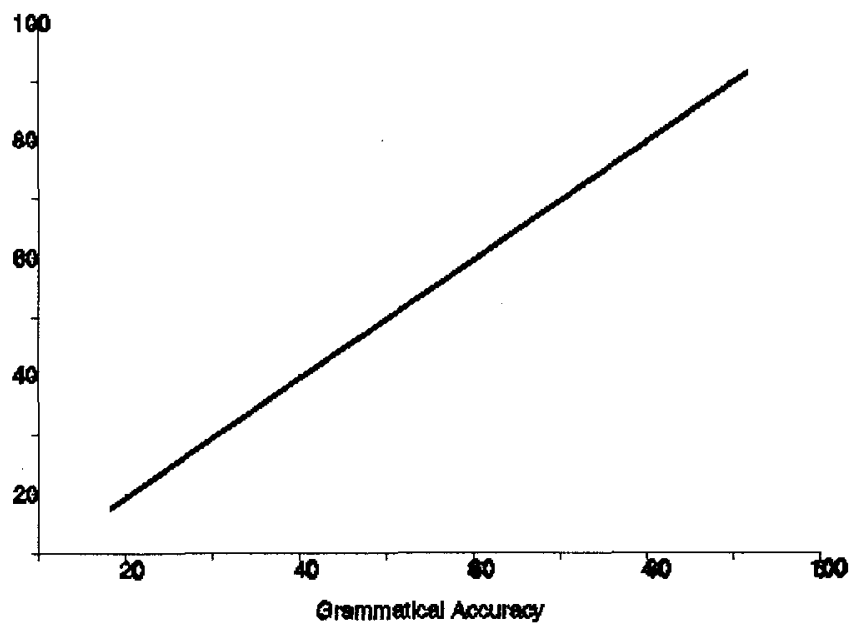

Figure 1a. CE and GA relation, sentence construction.

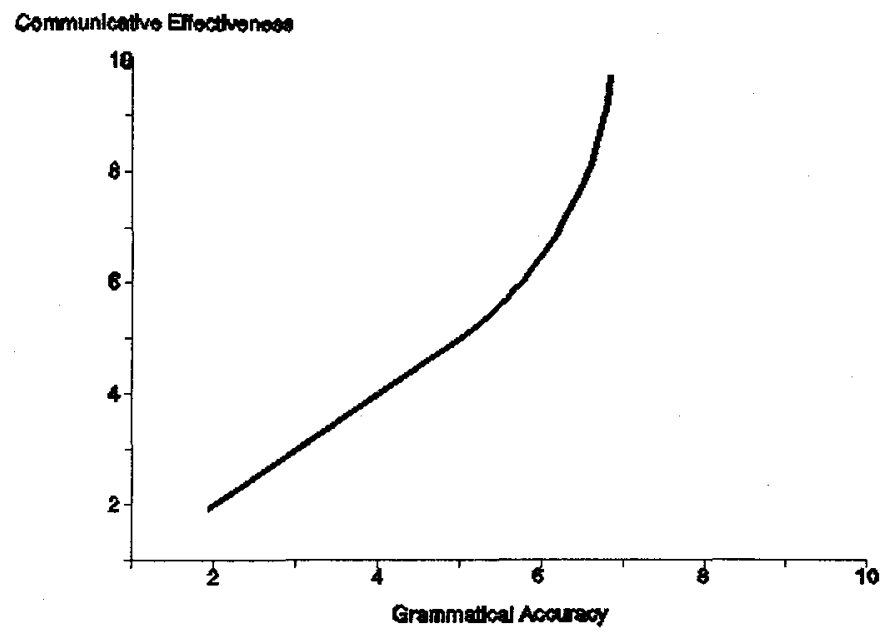

Figure $1 b . C E$ and $G A$ relation, story retell.

may indeed be utilized to enhance comprehensibility, but it is also possible to utilize other abilities instead. Thus high levels of GA may be "sufficient" to achieve high levels of CE in extended discourse, but high levels of GA are not 
"necessary." In the sentence construction task, high levels of CE were regularly associated with high levels of GA. It seems that GA was "necessary" for CE on this task.

To summarize this point, the relation between GA and CE is task dependent. On one type of task, GA and CE appear to develop simultaneously; on another, however, GA reaches a plateau with some subjects while CE continues to develop.

Within the framework of a communicative classroom, where communicative language teaching is interpreted as requiring strictly meaning-based activities, research shows that high levels of fluency can be achieved. Research also shows that certain components of linguistic knowledge and performance may not be fully developed (Lightbown \& Spada, 1993). In consequence, a number of communicative language teaching programs have incorporated form-focused activities into the curriculum in order to improve GA development.

If the findings of this study are not artifacts of the particular sample of learners, the test tasks selected, or the rating scales employed, some suggestions for instruction in communicative language teaching course may be inferred. These suggestions apply to communicative language teaching courses that include some focus on form as has been proposed by Scarcella and Oxford (1992) and Lightbown and Spada (1993). The results of this study suggest that students in such communicative classrooms would benefit from the inclusion of short-utterance teaching tasks. In these tasks form has communicative implications as a component for enhancing communicative effectiveness. That is, because utterances are not so predictable from context, the use of incorrect forms may well lead to a communication difficulty.

Teaching formal aspects of the second language should be done through short-utterance activities (i.e., those requiring brief-utterance responses or requiring students to react to short utterances). The primary reason for this is to give greater salience to matters of formal accuracy. Some students may be motivated to produce the L2 correctly and will accept their teachers' guidance on correctness; a more powerful influence, however, is success in communication. Fotos (1994) notes the "widely held theoretical assumptions that communicative interaction is fundamental to language acquisition" (p. 326). Littlewood (1981) claims that communicative activities improve motivation to learn and allow for natural learning, that is, "that many aspects of language learning can take place only through natural processes, which operate when a person is involved in using the language for communication" (pp. 17-18).

Considering the importance ascribed to communication, what we need is teaching activities in which formal errors may actually lead to communication failure, and not drills with attention on form. These are likely to be short-utterance instructional activities in which meanings must be communi- 
cated in brief, one- or two-sentence utterances. When communication fails, the student (perhaps together with the teacher) identifies the source of failure; only then can the teacher efficiently provide a correct form that will allow effective communication.

Such short-utterance tasks can require either production or comprehension. Comprehension tasks allow the teacher to select forms to focus on. The same degree of control is not generally possible with production tasks. These can, however, provide the opportunity for students to reveal their own particular language limitations. Because the focus in this study has been on oral ratings, a few suggestions for classroom speech activities are offered. The tasks would need to meet the following criteria:

1. be meaning based;

2. have a communicative goal (someone will respond to the message);

3. employ short utterances (not extended);

4. have a high language load (much information in short utterances).

The elicited responses could provide valuable information on correct and appropriate student use of form. Classroom suggestions include both simulations and screen type tasks. These may take the form either of exercises or of games. Whenever possible these activities should allow speakers to recognize a failure in communication through some actions of their interlocutors. Task types of this nature include:

1. leaving a message on a telephone answering machine;

2. reciting a list for someone else to use;

3. briefly describing a picture for a listener to draw;

4. having a listener put a series of pictures into an arbitrary sequence;

5. giving a brief description so that a listener can select a picture or object;

6. giving map directions to be followed.

The use of short-utterance communicative activities is certainly not the only way to focus on form. It may not even be very effective when teaching formal features of the language that ordinarily carry little meaning, for example, adverb placement in English. It seems, however, that these activities deserve to be more fully exploited when they can be employed.

This study investigated the relation between CE and GA in two different types of tasks in a communicative language teaching context. Certain trends in this relation have provided insight into possible leveling-off effects for GA in one of the task types investigated. This has suggested an approach to the question of how to teach formal accuracy. Accordingly, we have advocated the inclusion of short-utterance communicative activities for form-focused instruction in communicative classrooms.

In this study, we explored only one example of a difference in learner speech related to task types, namely, the importance of grammatical accuracy in relation to the textual redundancy of speech. This has led to the conclusion that short-utterance tasks with little textual redundancy may be 
useful for form-focused instruction. There are surely characteristics other than the degree of textual redundancy that render tasks effective for the learning of grammar, however. Effects of a variety of task types on language development need to be examined.

\section{Acknowledgments}

We wish to thank the following teachers who opened their classrooms to us: Beatrice Cahill, Françoise Caron, Robert Comeau, Lily Dabby, Anne Powell and Diane Tomlinson. Thanks also to the research team of Linda Bamber, Randall Halter, Joe Pater, Leila Ranta and Helen Raptis. This work was partially funded by the Fonds pour la formation de chercheurs et l'aide à la recherche of the Quebec Ministry of Education.

\section{Notes}

${ }^{1}$ A preliminary version of this paper was presented at the 21st Annual convention of the Societe pour la promotion de l'anglais, langue seconde, au Québec, Laval, Quebec, October 1993.

${ }^{2}$ It might be argued that neither task truly involves communication because the raters are familiar with the stimulus materials for both. However, the actual semantic content of student responses is not fully predictable for either task. A rater, in formulating a CE rating of a speech sample, must understand what the student has said. The tasks are, therefore, communicative.

${ }^{3}$ The questions appearing in the scales are those used during rating. Fuller descriptions were available to the raters and employed while they were trained to use the scales.

\section{The Authors}

Carolyn E. Turner is an assistant professor and Certificate Program Director in the Department of Education in Second Languages at McGill University. Her research focuses on testing and evaluation in second language education and on currculum development.

John A. Upshur is a professor of applied linguistics at the TESL Centre at Concordia University. His research focuses on assessment in second language education.

\section{References}

Bachman, L. (1990). Fundamental considerations in language testing. Oxford, UK: Oxford University Press.

Bachman, L. (1991). What does language testing have to offer? TESOL Quarterly, 25, 671-704.

Bachman, L., \& Palmer, A. (1984). Some comments on the terminology of language testing. In C. Rivera (Ed.), Communicative competence approaches to language proficiency assessment: Research and application (pp. 34-43). Clevedon, Avon: Multilingual Matters.

Brumfit, C. (1984). Communicative methodology in language teaching: The roles of fluency and accuracy. Cambridge, UK: Cambridge University Press.

Buczowska E., \& Weist, R. (1991). The effects of formal instruction on the second-language instruction of temporal location. Language Learning, 41(4), 535-554.

Bolduc, I. (n.d.). Anglais intensif. Greenfield Park: Commission scolaire catholique de Greenfield Park.

Canale, M. (1983). From communicative competence to competence language pedagogy. In J.C. Richards \& R.W. Schmidt (Eds.), Language and communication (pp. 2-27). London: Longman.

Canale, M., \& Swain, M. (1980). Theoretical bases of communicative approaches to second language teaching and testing. Applied Linguistics, 1, 1-47.

Columbia Broadcasting System. (1990). Arnold of the Ducks [Animated cartoon]. 
Cummins, J., \& Swain, M. (1986). Bilingualism in education. London: Longman.

Doughty, K. (1991). Second language instruction does make a difference: Evidence from an empirical study of SL relativization. Studies in Second Language Acquisition, 13, 431-496.

Enkvist, N.E. (1990). Seven problems in the study of coherence and interpretability. In U. Connor \& A.M. Johns (Eds.), Coherence in writing: Research and pedagogical perspectives (pp. 9-28). Alexandria, VA: TESOL.

Fotos, S. (1994). Integrating grammar instruction and communicative language use through grammar consciousness raising tasks. TESOL Quarterly, 28(2), 323-346.

Hymes, D.H. (1972). On communicative competence. In J.B. Pride \& J. Holmes (Eds.), Sociolinguistics (pp. 269-293). Harmondsworth, UK: Penguin.

Lightbown, P., \& Spada, N. (1993). How languages are learned. Oxford: Oxford University Press.

Linn R.L., Baker E.L., \& Dunbar S.B. (1991). Complex, performance-based assessment: Expectations and validation criteria. Educational Researcher, 20(8), 15-21.

Littlewood, W. (1981). Communicative language teaching: An introduction. Cambridge, UK: Cambridge University Press.

Munby, J. (1978). Communicative syllabus design. Cambridge, UK: Cambridge University Press.

Savignon, S.J. (1983). Communicative competence: Theory and classroom practice. Reading, MA: Addison-Wesley.

Scarcella, R.C., \& Oxford, R.L. (1992). The tapestry of language of learning. Boston, MA: Heinle \& Heinle.

Spada, N., \& Lightbown, P. (1989). Intensive ESL programmes in Quebec primary schools. TESL Canada Journal, 7(1), 11-32.

Tharp, R.G., \& Gallimore, R. (1988). Rousing minds to life: Teaching, learning and schooling in social context. Cambridge, UK: Cambridge University Press.

Tharp, R.G., \& Gallimore, R. (1989). Rousing schools to life. American Educator, 13(2), 20-25.

Turner, C., \& Upshur, J. (1992) Trait development in an intensive ESL course for adolescents: Grammatical knowledge and communicative ability. Chicago, IL: Central University. (ERIC Document Reproduction Service No. ED 345 499)

Upshur, J.A., \&.Turner, C.E. (in press). Constructing rating scales for second language tests. ELT Journal.

Vygotsky, L.S. (1956). Izbrannie psichologicheskie issledovania (Selected psychological research). Moscow: Izdatel'stvo Akademii Pedagogicheskikh Nauk.

Yorozuya, R., \& Oller, J. (1980). Oral proficiency scales: Construct validity and the halo effect. Language Learning, 30, 135-153.

Yule, G., Powers, M., \& Macdonald, D. (1992). The variable effects of some task-based learning procedures on L2 communicative effectiveness. Language Learning, 42(2), 249-277. 


\section{Appendix A}
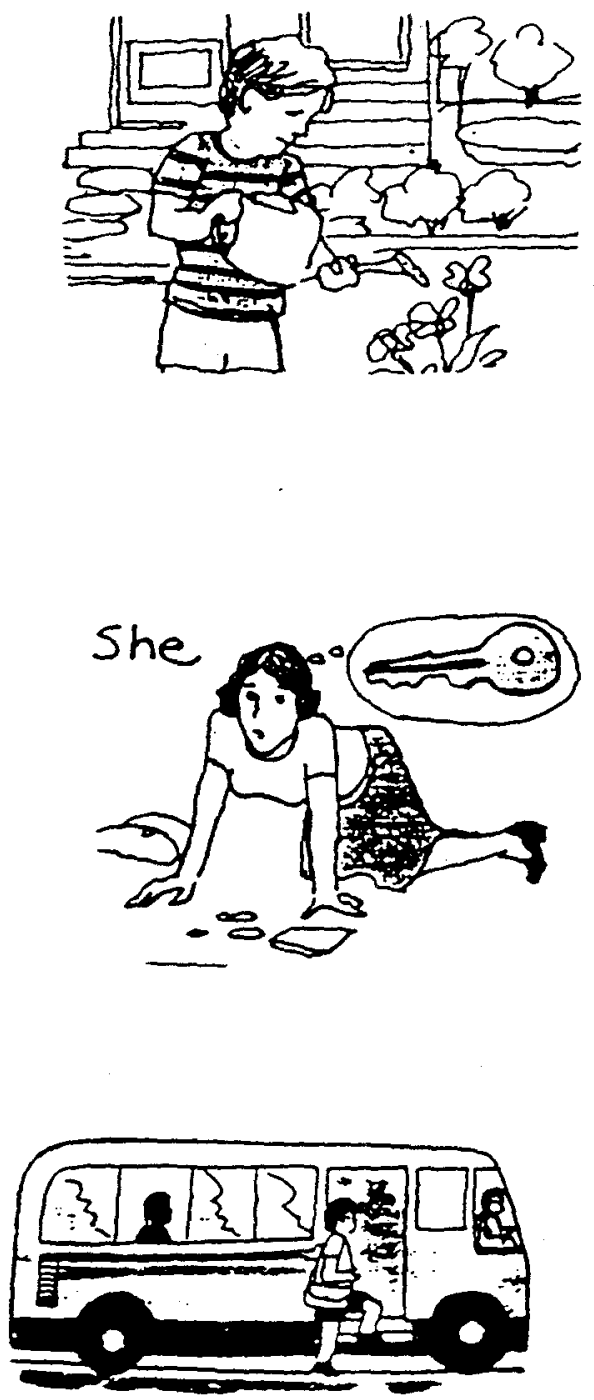

Tomorrow 


\section{Appendix B}

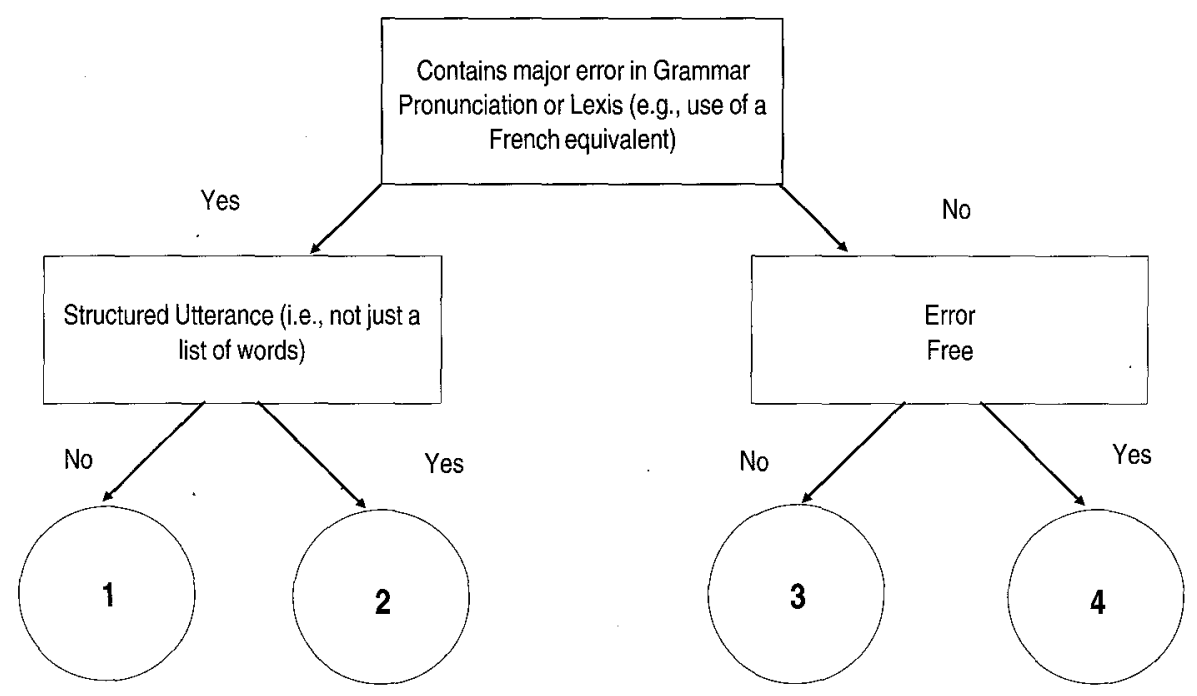

Rating scale for $G A$, sentence construction.

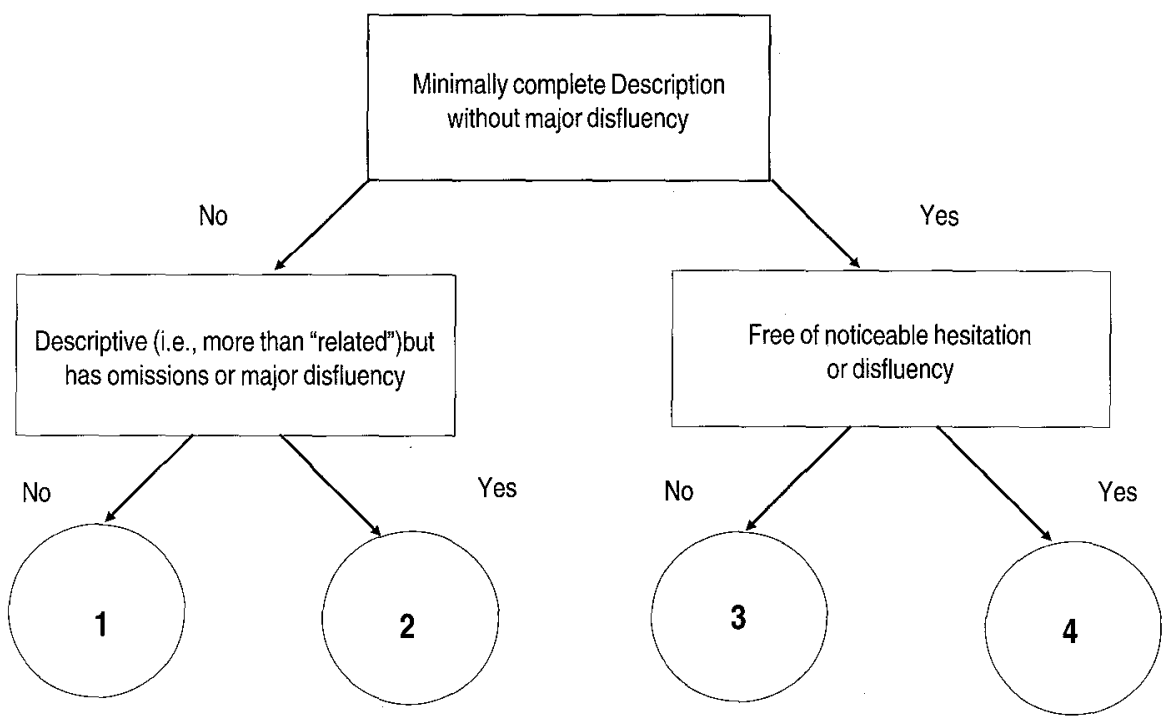

Rating scale for CE, sentence construction. 


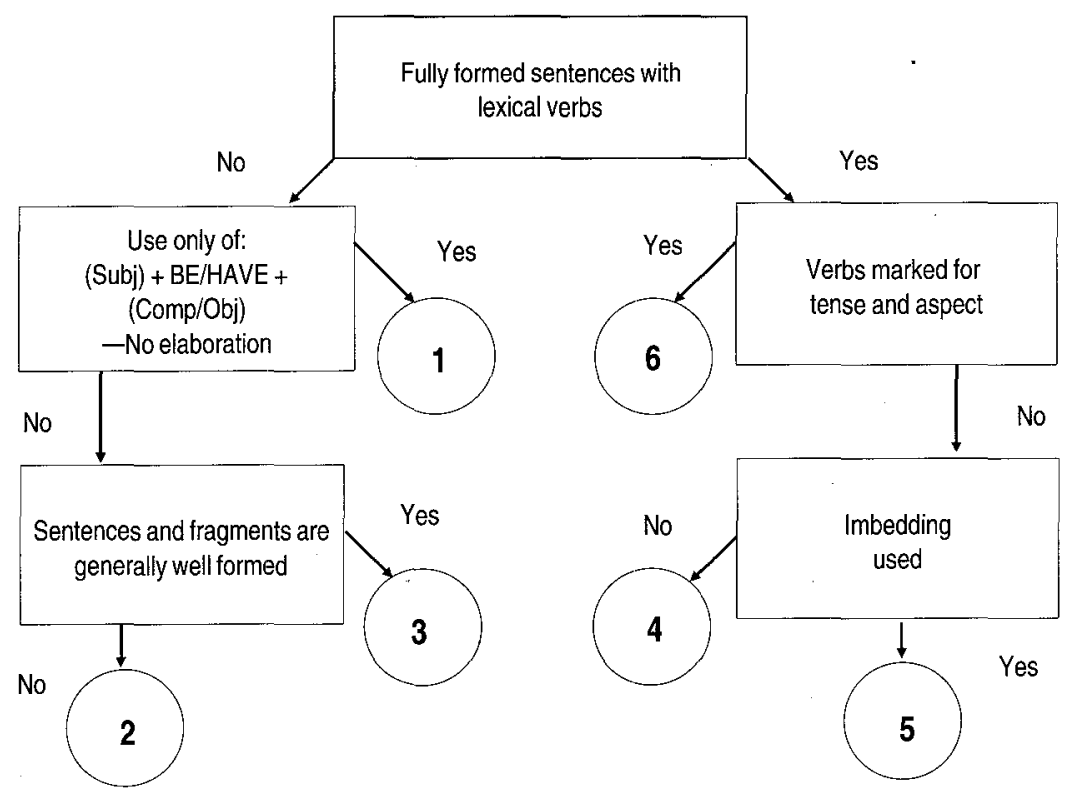

Rating scale for $G A$, story retell.

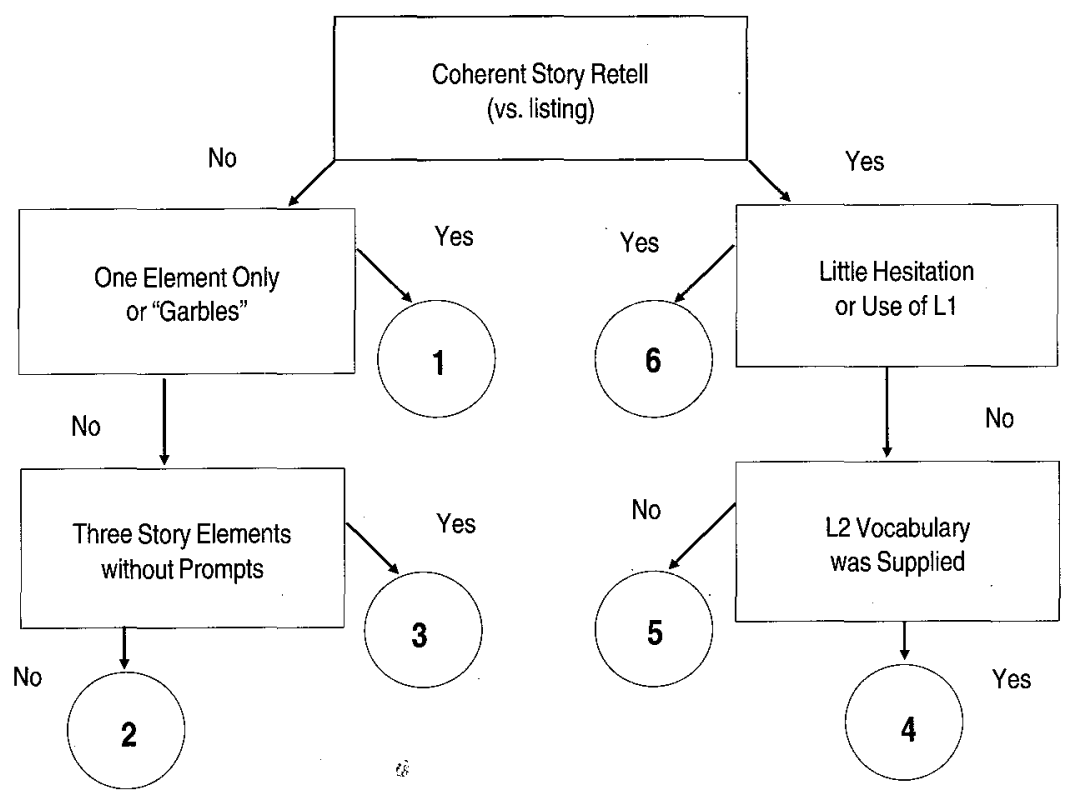

Rating scale for $C E$, story retell. 